\title{
Syro-Hittite iconography and food in practice
}

Alongside the rise of the independent Syro-Hittite kingdoms in the 1st millennium BC, a distinctive category of banquet scenes also developed in the northern Syria/southern Anatolia region. Regularly found on funerary steles, wall reliefs, and small objects, these scenes (Speisetischszene) are characterized by their representation of a food-laden table. Examined together, the examples from Zincirli - ancient Sam'al - and those from the surrounding patchwork of kingdoms suggest a shared ideology about feasting rituals. This talk explores how the recurring themes of these scenes, particularly foodstuffs, might reflect shared ideals and practices within a regional culture or even a shared Hittite heritage. Discussion of these issues will help establish how and why variations within the scenes (such as types of bread used) might be significant for the expression of local identities. In paying specific attention to mortuary examples, which occasionally include text, I hope to explore the extent to which the scenes may reflect food-related practices among the living. In the end, the consideration of food in art and text is not meant to ascribe concrete meanings to specific foodstuffs, but instead to direct my dissertation work on the archaeological evidence of domestic contexts, particularly the role of specialized cookware in daily and cultic practices, by suggesting possible ideological or practical motivations for variations in the household assemblages of Sam'al. 